\title{
A PARTICIPAÇÃO DA SOCIEDADE CIVIL NAS INSTITUIÇÕES COMUNITÁRIAS DO MERCOSUL (1991 - 2010)
}

\section{Ludmila Andrzejewski Culpi ${ }^{1}$}

\begin{abstract}
Resumo:
O presente artigo tem como tema a participação dos cidadãos nas instituições comunitárias do MERCOSUL. O problema a ser respondido é de que maneira a institucionalização do bloco impactou sobre a participação da sociedade civil organizada nas decisões comunitárias e se há uma maior preocupação em incluí-las. Neste sentido, o presente trabalho possui como objetivo geral analisar a dinâmica da participação dos cidadãos do MERCOSUL, por meio do estudo do funcionamento dos órgãos comunitários de caráter representativo. Coloca-se como objetivos específicos investigar: i) o envolvimento da sociedade civil na integração regional, a partir do reconhecimento da importância desse grupo para determinar os rumos do bloco; ii) a participação da sociedade civil nas reuniões dos órgãos comunitários; iii) o interesse dos organismos comunitários na promoção da participação popular e da questão social. O referencial teórico do artigo é a teoria construtivista das relações internacionais, que outorga importância à questão social e à participação da sociedade civil nos processos de formação de identidades. Os resultados encontrados são de que há um envolvimento maior da sociedade civil organizada, especialmente no Foro Consultivo Econômico-Social do MERCOSUL, porém ainda de maneira limitada. No âmbito do Parlamento do MERCOSUL, pouco se discute sobre a questão social e da sociedade civil e não há nenhum canal de participação direta.
\end{abstract}

Palavras-Chave: MERCOSUL, Sociedade civil, Foro Consultivo Econômico-Social, Parlamento do MERCOSUL.

\section{Resumen:}

Este artículo tiene como tema la participación de los ciudadanos en las instituciones comunitárias del MERCOSUR. El problema a ser contestado es cómo la institucionalización del bloque tubo impacto sobre la participación de la sociedad civil organizada en las decisiones comunitárias y si hay una mayor preocupación para incluirla. En este sentido, el presente trabajo tiene como objetivo principal analizar la dinámica de la participación ciudadana en el MERCOSUR, a través del estudio del funcionamiento de las instituciones comunitarias de carácter representativo. Tiene como objetivos específicos investigar : i ) la participación de la sociedad civil en la integración regional, a partir del reconocimiento de la importancia de este grupo para determinar la dirección del bloque; ii ) la participación de la sociedad civil en las reuniões de los órganos del MERCOSUR y iii ) el interes de los organismos comunitários en la promoción de la participación popular y la cuestión social. El marco teórico de este artículo es la teoría constructivista de las relaciones internacionales, que da importancia a las cuestiones sociales y la participación de la sociedad civil en los procesos de formación de la identidad . Los resultados encontrados son que hay una mayor participación de la sociedad civil, especialmente en el Foro Consultivo Económico - Social del MERCOSUR, pero todavia de manera limitada . En el marco del Parlamento del MERCOSUR, poco se discute acerca de la cuestión social y la sociedad civil y no hay ningun canal de participación directa.

Palabras-clave: Mercosur, Sociedad Civil, Foro Consultivo Económico-Social, Parlamento del Mercosur.

1 Mestre em Ciência Política pela Universidade Federal do Paraná - UFPR e Professora dos Cursos de Relações Internacionais e Ciência Política do Centro Universitário Internacional UNINTER, das disciplinas de Teoria das Relações Internacionais, Integração Regional, Blocos Econômicos e Introdução à Economia. E-mail: ludi_culpi@yahoo.com.br. 


\section{Abstract:}

This article has as its theme the participation of citizens in the community institutions of MERCOSUR. The problem to be answered is how the institutionalization of the block impact on the participation of organized civil society in decisions of the community institutions and if there is a greater concern to include them. In this sense, the present work has as main objective to analyze the dynamics of citizen participation in MERCOSUR, through the study of the functioning of the Community institutions of representative character. The specific purposes of this paper are to investigate: i) the involvement of civil society in regional integration, from the recognition of the importance of this group to determine the direction of the block; ii) the participation of civil society in the meetings of the community institutions; and iii) the interests of the institutions in promoting popular participation and the social issue. The theoretical framework of the article is the constructivist theory of international relations, which gives importance to social issues and civil society participation in the processes of identity formation. The results are that there is a greater involvement of civil society, especially in the Economic Social Consultative Forum of MERCOSUR, but also to a limited extent. Under the MERCOSUR Parliament, little is discussed about the social issue and civil society and there is no direct channel of participation.

Keywords: MERCOSUR, Civil Society , Economic- Social Consultative Forum, MERCOSUR Parliament

\section{INTRODUÇÃO}

O presente artigo tem como tema a participação dos cidadãos nas instituições comunitárias do Mercosul, a partir do momento da formação institucional do bloco até o ano de 2010. A questão a ser debatida é de que maneira a institucionalização do bloco impactou sobre a participação da sociedade civil organizada nas decisões comunitárias e se há uma maior preocupação com a questão social nessas decisões.

Neste sentido, o presente trabalho possui como objetivo geral analisar a dinâmica da participação dos cidadãos do Mercosul, através do estudo do funcionamento dos processos decisórios dos órgãos comunitários que permitem a participação dos cidadãos.

A hipótese apresentada pelo artigo é de que existe uma baixa participação da sociedade civil nas instituições comunitárias do Mercosul, devido principalmente ao baixo interesse dos cidadãos no processo de integração da América do Sul. Entretanto, essa realidade pode estar sendo alterada, em função de um crescente envolvimento dos agentes da sociedade civil no processo integracionista.

As alternativas de participação que os processos de construção política e de afirmação da cidadania oferecem aos indivíduos e aos estratos organizados da sociedade são considerados de fundamental importância no presente trabalho.

$\mathrm{O}$ artigo divide-se em duas seções. Na primeira seção, será apresentado o contexto histórico e político de criação do Mercosul, bem como a estrutura institucional do bloco. Ainda nessa seção, será exposto o referencial teórico e os conceitos pertinentes para o estudo do exercício da participação da sociedade civil nos organismos do Mercosul.

A segunda seção trata dos mecanismos que fomentam o exercício da participação cidadã no Mercosul. Para tanto, na primeira subseção, serão analisadas, sob o ponto de vista histórico, a origem do debate democrático no Mercosul, a partir da análise dos documentos ratificados no período. Na segunda subseção, será analisada a 
formação da sociedade civil e da identidade latino-americana e os esforços do Parlamento do Mercosul na defesa do maior envolvimento dos cidadãos e da questão social processo de integração sul-americano. Por fim, será analisada a participação do empresariado e dos sindicatos, no Foro Consultivo Econômico-Social, com o intuito de entender o lugar que a sociedade civil ocupa de maneira direta no Mercosul.

A fundamentação teórica do artigo será calcada na abordagem construtivista. Esses pressupostos nortearão a pesquisa com o intuito de verificar o espaço ocupado pelos cidadãos nas instituições de caráter comunitário. Os principais argumentos dessa teoria são que o mundo e as relações são socialmente construídos e que as identidades e interesses se alteram a partir das relações que os atores estabelecem (WENDT, 1992). Para tanto, serão usadas as obras de Alexander Wendt e Emanuel Adler.

Os documentos a serem analisados para o alcance dos objetivos propostos e verificação da hipótese do presente artigo são os diversos tratados constitutivos, os documentos do Fórum Consultivo Econômico-Social e do Parlamento e demais fontes primárias produzidas durante o período estudado que tratem do tema em questão. Teses, dissertações e fontes secundárias relacionadas ao presente artigo serão igualmente consultados.

Em termos metodológicos, será utilizada a análise de discursos e documentos das instituições do bloco do Cone Sul, que é recomendada pela teoria construtivista para compreensão dos interesses da sociedade civil latino-americana, para a posterior conformação das identidades que definem as estruturas e os resultados políticos.

\section{ASPECTOS CONTEXTUAIS E TEÓRICO-METODOLÓGICOS}

\subsection{Contexto Histórico e Político da Construção do Mercosul}

O Mercosul é o bloco de maior interesse para a América Latina, entretanto, enfrenta uma série de desafios em seu processo de integração. As origens da integração na América Latina remontam a Segunda Guerra Mundial, quando Argentina e Brasil almejaram a criação de uma união aduaneira entre as duas economias, que fracassou devido aos contrastes da situação dos dois países. Os esforços de integração na região partiram em grande maioria desses dois países, findando com a criação do Mercosul, com base no tratado de Assunção, de 1991 (PRESSER apud ORSINI, 1995). O Mercosul começou como uma aliança comercial com o objetivo de dinamizar a economia regional, e no futuro movimentar além de mercadorias e capital, força de trabalho e pessoas (ALMEIDA, 1993).

O bloco do Mercosul, como exposto, foi instituído mediante o tratado de Assunção de 1991, ratificado por quatro países: Brasil, Argentina, Paraguai e Uruguai. As iniciativas de integração propostas se observam nas relações bilaterais entre Brasil e Argentina, como o Tratado de Integração entre esses dois países (ALMEIDA, 1993).

De acordo com Abínzano (1993, p. 67): 


\begin{abstract}
Se cumple así uma antigua premonición que afirmaba que la integración sería posible cuando los dos "grandes" del sur decidieran liderar el proceso y se animaran a acercarse mutuamente, derribando el muro de las tradicionales desconfianzas y rivalidades (ABÍNZANO, 1993, p.67).
\end{abstract}

Os antecedentes mais remotos do Mercosul são encontrados na criação, em 1960, da Associação Latino-Americana de Livre Comércio (ALALC), tendo como participantes todos os países da América do Sul (com a exceção das Guianas) e o México. O objetivo principal da ALAC era uma mudança no modelo de desenvolvimento predominante até então na América Latina: o de economias com produção pouco diversificada, voltadas para o mercado dos países desenvolvidos. Entretanto, o projeto da ALALC encontrou obstáculos que a levaram ao fracasso, os quais se destacam a instabilidade política da região e a rigidez dos mecanismos definidos para a liberalização comercial (FLORÊNCIO e ARAÚJO, 1995).

Em fins da década de 1970, os países membros da ALALC negociaram um Tratado e criaram a Associação Latino-Americana de Integração (ALADI), que foi inaugurada em 1980. O objetivo da ALALC era o da total liberalização do comércio entre os membros, porém, ao contrário da iniciativa anterior, adotou mecanismos mais flexíveis para tal. Além da flexibilidade, outros dois fenômenos contribuíram para formar um ambiente propício à realização da integração latino-americana: a redemocratização, que ocorreu em quase todo o continente e a crescente diversificação da produção industrial, sobretudo dos países maiores (PEREIRA apud BRANDÃO e PEREIRA, 1996).

Nesse contexto mais promissor, os acordos sub-regionais se tornaram a principal força motora da ALADI. Nesse período, Brasil e Argentina iniciaram a negociação de reduções tarifárias recíprocas. Em 1986, firmou-se o Tratado de Cooperação Econômica, cujo intuito era incrementar o comércio em setores-chaves para a economia dos dois países, principalmente bens de capital, trigo e automóveis (VAZ, 2002).

Em 1988, Brasil e Argentina assinaram o Tratado de Integração, que previa a formação de um Mercado Comum entre os dois países, a adoção de uma tarifa externa comum e a coordenação das políticas macroeconômicas. Dessa maneira, o processo de integração adquiriu uma força sem precedentes. Em 1991, foi ratificado o Tratado de Assunção, que contou com a participação de Uruguai e Argentina. Manteve-se o objetivo de construir um Mercado Comum e estabeleceu-se um prazo para o 
cumprimento dessa meta, o dia 31 de dezembro de 1994. Designou-se esse projeto de Mercado Comum do Sul (VAZ, 2002).

As motivações para a criação do Mercosul foram várias e a primeira delas é a questão da proximidade geográfica, o que favorece o comércio e o desenvolvimento de um sistema de transportes adequado para esse fim. Além disso, o fato de não haver rivalidades étnicas, culturais ou religiosas entre os países foi um fator positivo para a configuração da integração. As rivalidades políticas haviam se dissipado com o fim dos regimes militares, a partir de meados dos anos 1980 (FIGUEIRAS, 1994).

Em um primeiro momento, o processo de negociações que culminou na criação do Mercosul foi realizado com base no plano político dos dois Estados que iniciaram a condução da integração, Brasil e Argentina, de modo bilateral. À medida que se consubstancia a cooperação, o processo evoluía para o plano político, econômico e estratégico. Deste modo, o processo de construção da integração esteve vinculado aos interesses de política externa e interna de ambos os Estados (VAZ, 2002).

O protagonismo central dos governos na formulação dos objetivos que orientavam a integração estendeu-se à arena de negociações diplomáticas, que se conformou em um ambiente de negociações de caráter intergovernamental, com participação coadjuvante de outros atores nacionais, tais como os da sociedade civil e os atores subnacionais (MALAMUD, 2003).

\subsubsection{Estrutura Institucional do Mercosul e a participação popular}

A estrutura institucional do bloco foi definida pelo Protocolo de Ouro Preto em dezembro de 1994, que criou as seguintes instituições: o Conselho do Mercado Comum, o Grupo Mercado Comum, a Comissão do Comércio do Comércio do Mercosul, a Comissão Parlamentar Conjunta, o Foro Consultivo Econômico e Social e os Comitês Técnicos (FLORÊNCIO e ARAÚJO, 1995).

O Conselho do Mercado Comum, composto pelos Ministros das Relações Exteriores dos Estados-Membros, traça as grandes linhas do processo de integração e assegura o impulso político para o aprofundamento. De acordo com AMARAL JÚNIOR (2000, p. 5):

Ao conferir personalidade jurídica-internacional ao Mercosul, o Protocolo de Ouro Preto atribuiu ao Conselho do Mercado Comum a função de órgão supremo da nova organização. Isso não lhe retirou, todavia, o caráter de conferência ministerial, que radica no sentido intergovernamental das instituições do Mercosul. Nessa qualidade, atua como instância política que fixa o sentido e curso da integração. 
O Grupo Mercado Comum possui funções executivas e é o principal órgão de implementação dos objetivos do Mercosul e de supervisão do seu funcionamento. É subordinado ao Conselho do Mercado Comum e as recomendações que adota são obrigatórias para todos os membros do bloco (FLORÊNCIO e ARAÚJO, 1995).

A Comissão de Comércio corresponde ao principal órgão técnico incumbido de administrar os instrumentos da política comercial comum. A CCM situa-se abaixo do Grupo Mercado Comum na pirâmide hierárquica. A Comissão exerce atividades consultivas e de assessoramento (FLORÊNCIO e ARAÚJO, 1995).

A Comissão Parlamentar Conjunta não faz parte diretamente do quadro institucional do Mercosul. Sua função principal é de acelerar os procedimentos legislativos para a entrada em vigor de normas estabelecidas pelo Mercosul e auxiliar o processo de harmonização das legislações, buscando um fortalecimento dos vínculos entre o Mercosul e os Parlamentos nacionais (FLORÊNCIO e ARAÚJO, 1995).

O Foro Consultivo Econômico-Social tem como objetivo ampliar a participação da sociedade nas decisões relativas à integração. O Foro é um órgão consultivo, contemplando uma vasta gama de assuntos sociais (FLORÊNCIO e ARAÚJO, 1995).

Por último, os Comitês técnicos assumem o caráter de órgãos de apoio e assessoria. Os Comitês reúnem dados para a elaboração de pareceres sobre a aplicação das políticas comerciais comuns, que não são obrigatórias (FLORÊNCIO e ARAÚJO, 1995).

A representação parlamentar, deixada a cargo da Comissão Parlamentar Conjunta, estava limitada à atuação do órgão como observador, portanto, sem independência para propor projetos de leis e políticas comunitárias. Esse órgão foi extinto com a criação do Parlamento do Mercosul, em 2005, que entrou em vigor em 2007,cujo objetivo era ampliar a integração, tornando-a mais democrática e incluindo a sociedade civil e o cidadão no debate sobre o processo de integração (SANCHEZ, 2005).

Além do Parlamento do Mercosul, o Foro Consultivo Econômico e Social representou um ambiente mais plural, formado por representantes de setores econômicos e sociais dos países membros. Essa instituição atua como um foro consultivo e tem competência para propor recomendações através do GMC. O Foro Consultivo e Social foi considerado um dos avanços mais significativos da estrutura institucional do Mercosul no que se refere à questão social, por abranger diversos grupos de interesse, embora tenha uma atuação restrita (SANCHEZ, 2005).

\subsection{Teoria Construtivista e a participação social na integração regional}


O principal argumento da teoria construtivista é de que tudo é socialmente construído e, dessa forma, tudo que se forma na arena política e social está diretamente relacionado às ações sociais. Esse paradigma confere papel central à sociedade civil e aos cidadãos na construção da política nacional e externa, embora o Estado continue sendo o ator mais importante no cenário internacional (RISSE apud DIEZ e WIENER, 2004).

De acordo com a teoria construtivista, a participação cidadã e a sociedade civil só podem ser analisadas dentro de um processo de integração a partir dos elementos sociais e não materiais, como as teorias convencionais da integração regional assinalam. Por essa razão, os construtivistas argumentam que as estruturas da política mundial são resultado de interações sociais, não sendo os Estados sujeitos estáticos, mas agentes dinâmicos no sistema internacional. Neste sentido, as identidades de todos os atores não são dadas, mas constituídas, por meio de práticas históricas complexas em constante alteração (ROSAMOND, 2000). Assim, a sociedade civil sul-americana é conformada a partir do contexto histórico que se desenvolve e nas interações sociais que ocorrem dentro das instituições comunitárias.

Os construtivistas entendem a integração regional como um conjunto de atores de uma mesma região com consciência, interesses, laços históricos e comuns, que se unem para conquistar de maneira mais eficiente seus objetivos, sobretudo no âmbito social e político (ADLER, 1999).

Uma das questões mais importantes para o aporte construtivista é desvendar qual o papel das ideias na vida social, ou seja, como ideias pautam a formação das identidades dos atores, a partir da qual definem seus interesses. $\mathrm{O}$ fator fundamental na política internacional é a distribuição de ideias nesse sistema (NOGUEIRA e MESSARI, 2005).

De acordo com Nogueira e Messari (2005, p.166) o ponto comum a todos os construtivistas é que o mundo não é predeterminado, mas construído à medida que os atores interagem, ou seja, que o mundo é uma construção social. O que determina os interesses e as preferências dos agentes é a interação entre os atores, isto é, os processos de comunicação entre agentes. Esse ponto é fundamental nessa análise, pois para se entender e analisar a participação e a legitimidade democrática é preciso conhecer os objetivos comuns dos atores e analisar a construção de uma identidade comum latino-americana que os guie.

Para Sônia de Camargo (2008, p. 479), o fato de a teoria construtivista utilizar ferramentas que avaliam o impacto da intersubjetividade e do contexto social em que 
ocorre a integração, aumenta a possibilidade de compreender as razões pelas quais a integração no Cone Sul possui um caráter não democrático.

Assim, o construtivismo confere importância à questão democrática, ao passo que a participação cidadã revela-se fundamental na construção de identidades que orientam a integração regional e as decisões de suas instituições, no âmbito da criação de políticas comunitárias.

Considerou-se adequada a utilização dessa perspectiva na análise do tema em função da adoção do pressuposto de que a institucionalização do Mercosul e os efeitos que tem sobre os campos da democracia e da participação não podem ser explicados apenas por fatores materiais. Dessa maneira, acredita-se ser fundamental recorrer a um pressuposto que atribua papel importante à construção das ideias e da necessidade da construção de uma identidade comum à sociedade civil sul-americana.

Nesse sentido, observa-se que um dos principais princípios que orientam a política externa do Brasil frente à integração regional é a percepção das elites e da sociedade civil. Deste modo, é fundamental incluir a sociedade civil representada por empresariado e sindicatos para que estes grupos passem a apoiar o processo de integração regional e verificar seus interesses sendo representados, reduzindo o "déficit democrático" existente nos organismos comunitários.

\subsubsection{Conceito de sociedade civil}

É necessário expor o conceito de sociedade civil que será utilizado no presente artigo. De acordo com Vieira (1997, p.44), o reaparecimento do conceito de sociedade civil nas últimas décadas associa-se a questão das lutas dos movimentos sociais contra os regimes ditatoriais que existiam no Leste Europeu e na América Latina.

Para Cohen e Arato (apud VIEIRA, 1992), a reconstrução de um conceito adequado de sociedade civil deve se basear em um modelo que distingue a sociedade civil tanto do Estado quanto da economia. Sob essa concepção, a sociedade civil é interpretada "como a esfera da interação social entre a economia e o Estado, composta principalmente pela esfera íntima (família), pela esfera associativa, movimentos sociais e formas de comunicação pública” (VIEIRA, 1992, p. 45).

\section{A CONSTRUÇÃO DA DEMOCRACIA E DA SOCIEDADE CIVIL NO MERCOSUL}

3.1. Origem do debate democrático e da inclusão da sociedade civil no Mercosul 
As preocupações acerca da participação social e da legitimidade democrática emanaram de maneira bastante tímida na construção da integração sul-americana. Essa modesta atenção dada à questão democrática revela-se na opção dos Estados fundadores do bloco por um modelo intergovernamental para suas instituições, evitando a transferência de suas soberanias estatais a organismos supranacionais. Evitou-se também a promoção da participação social, pela justificativa de que alguns grupos da sociedade poderiam se sentir prejudicados, o que os levaria a impedir o avanço do processo de integração (VIGEVANI e VEIGA, 1991).

Contudo, surgiram debates em torno do tema do "déficit democrático", explicitado na seção anterior, da mesma maneira que na União Europeia, o que levou os países a fomentarem a criação de espaços que tornassem a integração mais democrática e com enfoque mais social, como o Parlamento e o Foro Consultivo Econômico e Social.

Somente a partir de 2000, incluiu-se nas decisões dos órgãos comunitários, uma menção à participação e à democracia nos processos de decisão. Nesse sentido, o documento emitido pelo Conselho do Mercado Comum em 2000, 09/95, previa no item 3.2, que:

O aprofundamento do processo de integração requer uma crescente participação da sociedade. Nesse sentido, a Comissão Parlamentar Conjunta (CPC) e o Fórum Consultivo Econômico e Social (FCES) assegurarão a participação adequada dos setores envolvidos (DECISÃO DO CONSELHO DO MERCADO COMUM, 2000).

Todavia, era necessário desenvolver metas e programas para a inclusão da sociedade civil e nesse sentido, foi lançado, em 2003, o Programa de Trabalho do Mercosul 2004-2006, que consistia em um conjunto de linhas de ações para afirmar e expandir o projeto de integração. Neste documento, foi elucidada, pela primeira vez, a idéia de participação da "sociedade civil" (PROGRAMA DE TRABALHO DO MERCOSUL 2004-2006, 2003).

O tema da sociedade civil foi exposto no item 2.1 do Programa, com o objetivo de "Propiciar a participação da atuação da sociedade civil, levando em conta, entre outras, a Proposta apresenta pelo Foro Consultivo Econômico e Social, na data de três de outubro de 2003” (PROGRAMA DE TRABALHO DO MERCOSUL 2004-2006, 2003).

No que tange à preocupação em contemplar o cidadão, o documento afirma a necessidade de se fortalecer o Foro de Consulta e Concertação Política, para garantir a aprovação e a incorporação das normas relacionadas ao chamado Mercosul cidadão, 
com a integração social, educativa e cultural (item 2.4. PROGRAMA DE TRABALHO DO MERCOSUL 2004-2006, 2003).

Em 2006, surgiu a proposta de criação do Instituto Social do MERCOSUL, cujo objetivo central era o de combater a exploração sexual infantil, a segurança alimentar, a economia solidária. Nessa instituição os trabalhos teriam como prioridade a geração de trabalho e renda, com vistas a reduzir as assimetrias existentes entre os países do bloco (VÁZQUEZ, 2010).

Em 2007, o Instituto Social do MERCOSUL foi criado pelo Conselho Mercado Comum com a competência de "prestar colaboração técnica na elaboração e planificação de projetos sociais; indagar e apresentar à RMADS linhas e modalidades de financiamento disponíveis para a execução dos projetos; promover a investigação com a finalidade de apoiar a tomada de decisões na elaboração e na aplicação de políticas e programas sociais; promover a realização de encontros internacionais, regionais e nacionais sobre temas sociais; sistematizar e difundir as melhores experiências e práticas na matéria social do MERCOSUL, do continente e extracontinentais; recolher informação sobre a situação social na região; apresentar um relatório em cada ano das suas atividades à RMADS; e consultar o FCES sobre aqueles aspectos de sua competência e receber os projetos que este possa apresentar" (MERCOSUL/ CONSELHO MERCADO COMUM. No 03/o7).

Observa-se assim, um fortalecimento da questão social no bloco a partir da criação do organismo. Porém este teria apenas caráter consultivo, cujas decisões não seriam obrigatórias. Ademais, o documento de criação do Instituto Social do Mercosul definiu cinco eixos que passariam a guiar o trabalho dos ministérios de desenvolvimento social de cada país e do Instituto, quais sejam: economia solidária, infância, juventude, maioridade e segurança alimentar. O Instituto Social do Mercosul foi de fato instalado em 2009, consolidando a agenda social do Mercosul.

Outro importante mecanismo social do MERCOSUL é o Plano Estratégico de Ação Social do MERCOSUL (PEAS), cuja proposta foi apresentada pelos chefes de Estados na Cúpula de Córdoba de 2006 e rediscutida em 2008, na Reunião Ordinária do Conselho do Mercado Comum, quando foi criada a Comissão de Coordenação de Ministros de Assuntos Sociais do MERCOSUL com vistas a coordenar a elaboração do documento que foi aprovado apenas em 2010.

Esse Plano foi criado no âmbito da luta contra as desigualdades sociais e para assegurar direitos humanos, econômicos, sociais e culturais. Nesse sentido, o PEAS é formado por dez eixos e vinte e sete diretrizes que orientam a conformação de 
cooperação em políticas públicas (MERCOSUL/CONSELHO MERCADO COMUM. No 03/07).

Ainda em 2007, foi criado o Instituto MERCOSUL de Formação (IMEF), que tem o objetivo principal “contribuir para a construção da integração regional através da consolidação do mercado comum e da colaboração no processo de formação de uma cultura comunitária” (MERCOSUL/ CONSELHO MERCADO COMUM, No4/7). Observa-se ainda que o Instituto MERCOSUL de Formação tem como competência auxiliar a formação de funcionários públicos em temas relacionados à integração regional.

No âmbito da cultura observa-se pouca priorização da diplomacia cultural na agenda da política externa dos Estados-Membros do Mercosul. O ator relevante para promoção de estratégias visando a disseminação da cultura no bloco acaba sendo a sociedade civil, na figura de empresas que patrocinam iniciativas, como as Mostras de Cinema, a Bienal do Mercosul e a Feira do Livro, eventos realizados em Buenos Aires e Porto Alegre (SOARES, 2008).

Em maio de 2011, entrou em vigor o chamado Fundo de Financiamento do Setor Educacional do MERCOSUL (FOCEM), com a missão de financiar iniciativas de aprofundamento da integração regional no âmbito educativo, pela concessão de bolsas de intercâmbios a professores e estudantes (WANDERLEY, 2002).

As iniciativas apresentadas nesse artigo, como a criação do Instituto Social do MERCOSUL, PEAS, IMEF e FOCEM revelam que o bloco tem evoluído no âmbito do desenvolvimento de políticas de inclusão social (WANDERLEY, 2002).

\subsection{A Formação da Sociedade Civil e da Identidade Latino-Americana}

A construção de uma sociedade civil na América Latina está ligada a idéia de luta contra um Estado intervencionista, pois este representa um obstáculo para a afirmação plena dos interesses empresariais dominantes. Os interesses desses empresários estão vinculados às idéias de acumulação de capital sem regulação estatal e de políticas que priorizem a valorização do capital transnacional sobre o interesse dos trabalhadores de elevar salários (CASTILLO, 1996).

Por parte dos trabalhadores e dos demais grupos sociais também está presente o interesse na redução do controle do Estado sobre as empresas públicas, os sindicatos, as organizações políticas, sociais e culturais (CASTILLO, 1996).

Com relação à participação da sociedade civil nas instituições comunitárias apenas duas permitem uma participação direta, enquanto outra possibilita à sociedade exercer influência sobre suas decisões. Na primeira categoria, enquadra-se o Foro 
Consultivo Econômico-Social, pois é o único órgão que envolve setores da sociedade em seus grupos de trabalho. O Parlamento do Mercosul corresponde à segunda categoria, porque permite aos grupos da sociedade civil observarem seus plenários, contudo, não oferece a eles espaço para se manifestar. Entretanto, a sociedade civil pode atuar dentro do Parlamento do Mercosul exercendo influência sobre os deputados, ou mesmo por meio de elementos exógenos, como a mídia (SANCHEZ, 2005).

Pode-se verificar uma presença ativa de forças da sociedade civil no Mercosul e o surgimento de novas modalidades de articulação desses segmentos sociais com o Estado, que se diferenciam de acordo com as especificidades de cada Estado membro do Mercosul (WANDERLEY e VIGEVANI, 2005).

Os dois atores estratégicos, que merecem maior destaque na análise da sociedade civil na América do Sul, são o empresariado e os sindicatos de trabalhadores. O relacionamento desses agentes com governo acontece devido à influência destes nos diversos âmbitos da sociedade, e por meio das diversas formas de atuação: a presença nos Parlamentos, divulgação de seus interesses e posicionamentos na mídia, participação em conselhos, discussões com governantes (WANDERLEY e VIGEVANI, 2005).

Com relação ao empresariado, Wanderley e Vigevani (2005, p.230) apontam que a inserção das empresas brasileiras no Mercosul se deu mais pelas iniciativas individuais do que por uma estratégia organizada do setor. As empresas de grande porte, que mais se destacam, exploram as oportunidades oferecidas de maior lucratividade que surgem no âmbito do Mercosul.

Por sua vez, os pequenos e médios empresários estão sujeitos à falta de informação disponível sobre as oportunidades fomentadas pelo bloco. Para solucionar essa questão, criou-se a Associação de Empresas Brasileiras para a Integração no Mercosul, cuja finalidade central é oferecer informações e capacitar os empresários para a importância da integração e o impacto da mesma sobre seus negócios. Ainda nesse sentido, foi criado o Conselho de Empresários da América Latina,em 1993, pela iniciativa de empresários brasileiros e argentinos. Verifica-se uma maior atuação dos estados de Santa Catarina e Rio Grande do Sul, devido a proximidade territorial com o Cone Sul (WANDERLEY e VIGEVANI, 2005).

No que tange aos trabalhadores, desde as primeiras iniciativas de integração, este grupo demonstrou seu apoio, de modo crítico, com o objetivo de consolidar a integração regional como uma necessidade, entretanto, questionando o tipo de integração que se forma, para afastá-la do esquema neoliberal. A Força Sindical do Brasil, por exemplo, ofereceu apoio maior à formação do bloco do que as demais 
associações dos outros Estados membros do Mercosul. Na esfera organizacional, as associações sindicais dos Estados membros fortaleceram sua articulação conjunta por meio da criação da Coordenadora de Centrais Sindicais do Cone Sul (CCSCS). A partir da formação dessa instituição, os trabalhadores passaram a participar com uma freqüência maior das reuniões relevantes no âmbito do Mercosul, incorporando na agenda do bloco as demandas desse setor e da sociedade civil de maneira geral (WANDERLEY e VIGEVANI, 2005).

\section{A SOCIEDADE CIVIL E AS INSTITUIÇÕES COMUNITÁRIAS DO MERCOSUL}

\subsection{A questão social, a sociedade civil e as decisões do Parlamento do Mercosul}

Em função da inexistência de um espaço para consulta à sociedade civil sobre as decisões tomadas pelo Parlamento do Mercosul, opta-se por uma análise das decisões do órgão, desde sua constituição em 2006 até 2010, com vistas a observar se o órgão coloca como prioridade a expansão de espaços públicos de contestação no bloco e a promoção da questão social, a partir da elaboração de documentos referentes ao tema.

Na reunião Constitutiva do Parlamento do Mercosul, em 2006, fez-se menção à sociedade civil, colocando como objetivo do órgão "estimular a formação de uma consciência integracionista na sociedade civil dos países da região”. O documento apresenta ainda que "A criação do Parlamento do Mercosul constituirá fator fundamental: para maior legitimação dos processos decisórios, mediante a ampliação da participação da sociedade; e para a dinamização e o aprofundamento da integração”. Contudo, não apresenta a forma como será implementada e aprofundada a participação da sociedade civil (ATA DA REUNIÃO CONSTITUTIVA DO PARLAMENTO DO MERCOSUL, 2006). Deste modo, observa-se o caráter profundamente intergovernamental da instituição no momento da sua criação, sem a preocupação com a atribuição de um caráter supranacional ao bloco.

No documento prevê-se que, "ao final de 2010, na segunda fase da transição, entrará em vigor a "representação cidadã". Cada país elegerá diretamente, pelo voto popular, os seus representantes no Parlamento, conforme a legislação de cada EstadoParte” (ATA DA REUNIÃO CONSTITUTIVA DO PARLAMENTO DO MERCOSUL, 2006, p.234). Essa meta revela a necessidade de conferir um maior caráter democrático ao Parlamento, em função do debate acerca do "déficit democrático e social”. Porém, 
até 2012 as eleições diretas aconteceram apenas no Paraguai, com previsão para acontecerem em 2014 no Brasil, porém ainda sem diretrizes eleitorais definidas.

Em 2007, analisando-se as atas das oito reuniões ordinárias realizadas, faz-se poucas referências à sociedade civil, normalmente relacionada à convocação da participação da mesma, porém sem determinação da forma como seria realizada. Menciona-se também a questão da construção de uma identidade e de uma cidadania comuns. Com relação à defesa dos direitos humanos, na oitava seção foi aprovada uma declaração que condena o genocídio na Armênia, ocorrido entre 1915 e 1923, como crime contra a humanidade. Outras questões discutidas foram a inclusão dos estados nordestinos, a erradicação da pobreza nos países e a necessidade de estabelecimento de um Parlamento da UNASUL (ATAS DAS REUNIÕES ORDINÁRIAS DO PARLAMENTO DO MERCOSUL, 2007).

Na nona seção ordinária, realizada no ano de 2008, é reconhecida a falta de credibilidade do Parlamento, por não ter conseguido permear a sociedade civil através de resultados concretos. Recomenda-se ainda para solução da questão, que a sociedade civil seja incluída no debate pelos Parlamentos nacionais e com apoio do Fundo Estrutural do Mercosul. Na décima quinta seção do ano de 2008, apresenta-se a proposta para criação de um Conselho de Defesa Sul-Americano (ATAS DAS REUNIÕES ORDINÁRIAS DO PARLAMENTO DO MERCOSUL, 2008).

$\mathrm{Na}$ décima sexta reunião realizada em 2009, foi apresenta a necessidade de analisar a crise financeira global. Sobre essa questão foi levantado que a sociedade organizada estaria reclamando a intervenção do Parlamento do Mercosul sobre o tema. Para isso a Comissão Parlamentar que trata das questões sociais foi convocada para discutir o tema e apresentar ao plenário uma proposta de recomendações a serem seguidas pelos Estados. Na décima sétima reunião, com relação à questão social foi aprovado um documento que reprova as ações do movimento paraguaio dos sem-terra. (ATAS DAS REUNIÕES ORDINÁRIAS DO PARLAMENTO DO MERCOSUL, 2009).

Na vigésima segunda reunião, realizada em 2010, foi criada a Corte de Justiça do Mercosul, que permite a pessoas físicas e jurídicas recorrer a mesma, caso algum membro do Mercosul não cumpra as normas acordadas. Sendo assim, passa-se a delinear um ordenamento jurídico, que favorece a integração e o cumprimento das leis e constrange os Estados a descumprirem os acordos e a violarem os direitos da sociedade civil (ATAS DAS REUNIÕES ORDINÁRIAS DO PARLAMENTO DO MERCOSUL, 2010).

Deste modo, percebe-se a partir da análise das atas das reuniões dos parlamentares do Mercosul, a insuficiência das discussões no âmbito do Mercosul a 
respeito da questão social e da inclusão da sociedade civil no âmbito comunitário, que limitam-se à retórica de reforçar a necessidade de assegurar um espaço democrático e de defesa de direitos humanos, contudo, sem esboçar ações concretas para o cumprimento dessas metas.

\subsection{A participação da sociedade civil no Foro Consultivo Econômico-Social}

Como apresentado anteriormente, o Foro Consultivo Econômico-Social (FCES), é o órgão de representação dos setores econômicos e sociais dos Estados Partes do Mercosul. Em sua estrutura institucional é composto pelas Seções Nacionais, dentre as quais uma delas coordena os trabalhos do organismo. Atualmente a Seção Nacional Coordenadora é a Argentina. A estrutura institucional do FCES é composta pelo Plenário do Foro, o qual poderá constituir órgãos de assessoramento. O Plenário do Foro é o órgão superior do FCES, cuja competência é a tomada das decisões necessárias para assegurar o perfeito cumprimento do estipulado no Protocolo de Ouro Preto (REGIMENTO INTERNO DO FORO CONSULTIVO ECONÔMICO-SOCIAL DO MERCOSUL, 1996).

Conforme a composição prevista pelo Protocolo de Ouro Preto, o mecanismo resguardado para participação direta e exclusiva de outros atores que não fazem parte da burocracia estatal é o Foro Consultivo Econômico-Social (FCES). A participação nessa organização está, todavia, limitada a trinta e seis representantes dos "setores econômicos e sociais", sendo que a cota estabelecida para cada Estado-membro é de nove participantes (SANCHEZ, 2005).

Outra possibilidade de participação direta são as reuniões preparatórias dos Subgrupos de Trabalho (SGTs) e suas respectivas Comissões, que atuam no âmbito do FCES e da Secretaria do Mercosul, vinculados ao Grupo Mercado Comum. Em 2005, existiam quatorze SGTs, relacionados a temáticas variadas e quarenta e cinco Comissões vinculadas aos primeiros. A participação nesse tipo de reuniões está restrita a apenas três representantes da sociedade civil por encontro. No mesmo sentido, é possível a participação de representantes da sociedade civil nas reuniões dos Comitês Técnicos, que podem ser especialistas solicitados para prestar assessoramento aos membros do Comitê ou mesmo outros representantes do setor privado, que podem ser convocados para emitir opiniões (SANCHEZ, 2005).

O movimento sindical atuou ativamente na criação do FCES, que entrou em vigor em 1996, pois a proposição de sua criação partiu de uma representante do movimento que participou das reuniões para a criação do Protocolo de Ouro Preto. No FCES diversos atores participam como sindicatos, empresários, consumidores, 
cooperativas, sociedades científicas e acadêmicas e ONGS, por meio de manifestações por recomendações ao Grupo Mercado Comum e por iniciativa própria (CASTRO apud LORENZETTI, 2000).

Entretanto, a grande maioria dos representantes são membros de sindicatos e do empresariado, o que demonstra que a presença de organizações sociais de outro caráter, como Organizações não-governamentais é pouco significativa no FECS (CASTRO apud LORENZETTI, 2000).

Por exemplo, em 1996, a delegação Brasileira no FCES estava composta por: CUT, CGT, Força Sindical, Confederação Nacional da Agricultura, Confederação Nacional do Comércio, Confederação Nacional da Indústria, Confederação Nacional dos Transportes, IDEC (Instituto Brasileiro de Defesa do Consumidor, Federação Nacional das Seguradoras, e SBPC (Sociedade Brasileira Para o Progresso da Ciência), isto é, a maioria parte do empresariado e do movimento trabalhista (CASTRO apud LORENZETTI, 2000).

O caráter consultivo da instituição, que apenas emite recomendações ao Grupo Mercado Comum, revela o espaço restrito de intervenção direta no bloco dado aos grupos da sociedade civil mercosulina (SANCHEZ, 2005).

\section{CONCLUSÕES}

Conclui-se a partir da análise dos documentos que abordam a questão social e das instituições criadas para defender essa questão e expandir a sociedade civil, que desde a criação do Mercosul houve um avanço na consolidação da dimensão social. Essa maior promoção de temas sociais revela a mudança da identidade dos atores sociais do bloco (as instituições e os Estados) que passaram a atribuir maior importância à questão social e democrática.

Porém, esse avanço se revela pouco significativo devido à falta de institucionalização do bloco e de mecanismos para promoção de políticas sociais comuns e de maior envolvimento da sociedade organizada. No âmbito da participação da sociedade civil, revelou-se, pela análise das atas das reuniões do Parlamento do Mercosul e dos compromissos traçados, a baixa inclusão de questões sociais e de defesa dos interesses da sociedade civil organizada, o que comprova a existência de um "déficit social e democrático" no bloco.

Para equilibrar a falta de compromisso do Parlamento do Mercosul com a sociedade civil, em outra esteira está o Foro Consulto Econômico-Social, que pela pesquisa revelou-se a única instituição que oferece espaço de participação e consulta a 
atores da sociedade civil, em especial os sindicatos e o empresariado. Todavia, a falta de legitimidade do organismo, que apenas emite recomendações não obrigatórias aos Estados, não promove um aprofundamento real da participação dos atores sociais. Nesse sentido, é necessário atribuir maiores competências a essa instituição, para assim, reduzir o "déficit democrático" verificado na análise da atuação do Parlamento do Mercosul.

\section{REFERÊNCIAS BIBLIOGRÁFICAS:}

ABÍNZANO, R. Caminos de La Integración Latinoamericana. Posadas: Universidad Nacional de Misiones, 1993.

ADLER, E. O Construtivismo no Estudo das Relações Internacionais. Lua Nova, $\mathrm{n}^{\mathrm{o}}$ 47, 1999.

ALMEIDA, P. R. de. O Mercosul no Contexto Regional e Internacional. São Paulo: Aduaneiras, 1993.

AMARAL JUNIOR, A. do. Mercosul: Características e Perspectivas. Revista de Informação Legislativa, Brasília, n. 146, 2000.

CAMPOS, E. N. O lugar do cidadão nos processos de integração: o déficit social da Comunidade Européia e do Mercosul. Belo Horizonte: Mandamentos, 2012.

CASTILLO, G. Los trabajadores y el Mercosur. Buenos Aires: Corregidor, 1996.

CASTRO, M. S. P. “Movimento sindical no Mercosul: trajetória e perspectivas de ação”. IN: LORENZETTI, J.; FACCIO, O. L. (orgs.) O Sindicalismo na Europa, Mercosul e Nafta. São Paulo: LTR, 2000.

FIGUEIRAS, M. S.. O Mercosul no Contexto Latino-americano. São Paulo: Atlas, 1994.

FLORENCIO, S. A.; ARAÚJO, E. H.. Mercosul Hoje. São Paulo: Alfa Omega, 1996.

IANNI, O.. A sociedade global. Rio de Janeiro: Civilização Brasileira, 1992.

MALAMUD, A. Integração regional na América Latina: teorias e instituições comparadas. In: ESTEVES, P. L. (org.). Instituições Internacionais: segurança comércio e integração. Belo Horizonte: Editora PUC-Minas, 2003.

NOGUEIRA, J. P. e MESSARI, N. Teoria das Relações Internacionais. Rio de Janeiro: Elsevier, 2005. 
PEREIRA, L. V. “Tratado de Assunção: resultados e perspectivas”. In: BRANDÃO, Antônio S. P. e PEREIRA, Lia Valss (org.). MERCOSUL: Perspectivas da Integração. Rio de Janeiro: Editora da Fundação Getúlio Vargas,1996.

PRESSER, M. F. “Abertura Externa e Integração Regional: O caso do Mercosul In: ORSINI, Salvador (org). El Mercosur: um desafio. Brasília: Departamento de Brasília de Estudos Sócio-Econômicos e Políticos, 1995.

RISSE, T. Social Constructivism and European Integration. In: Diez, Thomas e Wiener, Antjie (org.) European Integration Theory, Oxford, 2004.

ROSAMOND, B. (2000) Theories of European Integration. Basingstoke: Macmillan, 2000.

SANCHEZ, M. Pontos críticos da participação da sociedade civil no Mercosul. São Paulo: FGV, 2005.

SOARES, M. S. A. A diplomacia cultural no Mercosul. Rev. bras. polít. Int., vol. 51, n.1, p. 53-69, 2008.

VAZ, A. C. Cooperação, Integração e Processo Negociador: A Construção do Mercosul. Brasília: Fundação Alexandre de Gusmão, 2002.

VIEIRA, L. Cidadania e globalização. São Paulo: Record, 2002.

VIGEVANI, T. e VEIGA, J. P.. Mercosul e os interesses políticos e sociais. São Paulo em perspectiva. Vol. 5, n. 3, São Paulo, SEADE, 1991.

VILLA, R. D. Formas de influência das ONGs na política internacional contemporânea. Revista de Sociologia e Política, Curitiba, $\mathrm{n}^{0}{ }_{12}, 1999$.

WANDERLEY, L. E.; VIGEVANI, T. Governos Subnacionais e sociedade civil: Integração Regional e Mercosul. São Paulo: EDUC, 2005.

WANDERLEY, L. E. Mercosul e sociedade civil. São Paulo em Perspec. vol.16, n.1, pp. 63-73, 2002.

WENDT, A.. Anarchy is what States Make of it: The Social Construction of Power Politics. International Organization, vol. 46, no. 2, 1992. 